\title{
The FOMC: Preferences, Voting, and Consensus
}

\author{
Ellen E. Meade
}

\begin{abstract}
In this paper, the author develops and uses an original dataset collected from the internal discussion of the Federal Reserve's monetary policy committee (the Federal Open Market Committee [FOMC] transcripts) to examine questions about the Committee's behavior. The data show that Chairman Alan Greenspan's proposals, after Committee discussion, were nearly always adopted unmodified in the formal vote. Despite the external appearance of consensus with little disagreement over decisions and an official dissent rate of 7.5 percent, the data reveal that the rate of disagreement in internal Committee discussions was quite high-on the order of 30 percent for discussions of the short-term interest rate. And, under the assumption that FOMC voters assigned a higher priority to their preferences for the short-term interest rate than for the bias in the policy directive, it can be shown that this bias was important for achieving consensus, which supports and extends the results of Thornton and Wheelock (2000). Thus, the novel dataset described in this paper helps to shed some light on the internal workings of the FOMC in the Greenspan years.
\end{abstract}

Federal Reserve Bank of St. Louis Review, March/April 2005, 87(2, Part 1), pp. 93-101.

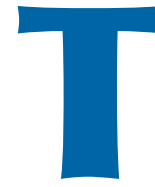

he Federal Reserve's monetary policy committee, the Federal Open Market Committee (FOMC), is generally viewed as a group in which dissent is infrequent and many decisions are taken unanimously. In writing about the transparency practices of the world's major central banks, Blinder et al. have argued (2001, p. 39) that "it is widely known that individual [FOMC] members often do not vote their true preference. Instead, each committee member decides whether to support or oppose the chairman's [Alan Greenspan's] policy recommendation, which is almost always made first. And Fed traditions dictate that a member should 'dissent' only if they find the majority's (that is, the chairman's) opinion unacceptable." In this paper, I construct and examine a dataset of pref- erences drawn from the transcripts of FOMC meetings during the Greenspan years to investigate the claim that the votes cast by Fed policymakers do not reflect their "true preference."

In FOMC meetings during Alan Greenspan’s tenure as Chairman and for which verbatim transcripts have been made available, the structure of the meeting has been more or less fixed with two "rounds" of discussion. ${ }^{1,2}$ During the first round of discussion, participants offered their views on the economic situation and frequently positioned

\footnotetext{
1 For more detail, see FOMC transcripts and Meyer (2004).

2 Over the period examined, the FOMC set long-run monitoring ranges for the monetary aggregates (as required by the HumphreyHawkins Act) at its first and fourth meeting each year; the determination of these ranges was taken up in a separate round of discussion.
}

Ellen E. Meade is an associate fellow at Chatham House and a guest scholar at the Brookings Institution and thanks Chris Crowe, Bill English, Petra Gerlach-Kristen, Charles Goodhart, Jakob de Haan, Marco Haan, Peter Kenen, Brian Madigan, Bob Rasche, Daniel Seidmann, Nathan Sheets, Paola Subacchi, James Talbott, Dan Thornton, Ted Truman, David Wheelock, and seminar participants at the University of Groningen and Chatham House for comments on an earlier version of this paper. She also thanks Chris Crowe and Cathy Tunis for expert assistance and gratefully acknowledges research support from the American Institute for Contemporary German Studies, Deutsche Akademische Austausch Dienst, and Economic and Social Research Council. The author conducted this research, in part, while visiting the Federal Reserve Bank of St. Louis. The views expressed here do not necessarily reflect official positions of the Federal Reserve Bank of St. Louis, the Federal Reserve System, or the Board of Governors.

(c) 2005, The Federal Reserve Bank of St. Louis. 
themselves with respect to a forecast prepared by the Fed staff. In addition, the presidents of the 12 Federal Reserve Banks provided some specific information about economic developments in their regions. Greenspan typically did not speak during this first round and, although he called on the other participants in no fixed order, it is generally the case that the Reserve Bank presidents spoke prior to the Board members.

The second round of the meeting was devoted to the discussion of policy options and culminated in a formal vote. After a staff presentation on policy options, Greenspan provided an extended discussion of his views before making a policy recommendation. Other participants followed in no fixed order. ${ }^{3}$ At the end of the second round, Greenspan made a final proposal and a formal vote was taken, with the Chairman casting his vote first. ${ }^{4}$ Although there are only 12 voting members on the FOMC at any given time, it was typical for all 19 policy officials (the seven Board members and the 12 Bank presidents) to participate in both rounds of the discussion. Over the period examined in this study, the minutes of each meetingincluding the operational policy directive as well as the votes cast by policymakers-were published about six weeks after each FOMC meeting.

Unlike the minutes, which are brief and report discussion without attribution, the published transcripts provide a relatively complete account of FOMC meetings. The transcripts are, for the most part, verbatim, although they have been lightly edited to provide clarification (when necessary) and to excise discussion of specific sources (when release of this information could undermine the FOMC's access to information ${ }^{5}$ ). What becomes clear when reading the transcripts is that, during the second round of the discussion, all

\footnotetext{
3 It was often the case that the president of the Federal Reserve Bank of New York (who serves as the FOMC's vice chairman) was the second speaker.

4 The FOMC's vice chairman voted second, followed by other voters in alphabetical order.

5 Greenspan (1995) has indicated that material is redacted from the transcripts "primarily to protect the confidentiality of foreign and domestic sources of intelligence that would dry up if their information were made public. Included in that category is some information supplied to us by foreign central banks and other government entities."
}

participants generally have voiced an explicit policy preference. Thus, collecting these preferences offers the possibility to look at "opinions" rather than votes.

For the 1989-97 period, I examined two "dimensions" to the policy under consideration at each FOMC meeting: the level of the short-term interest rate, or federal funds rate, and the "bias" or "tilt" in the policy directive. Both of these "dimensions" were contained in the policy directive that the FOMC issued internally at the conclusion of each meeting to direct the Open Market Desk at the Federal Reserve Bank of New York in its implementation of monetary policy. Prior to August 1997, the directive did not refer explicitly to the FOMC's objective for the federal funds rate, but was written instead solely in terms of the desired degree of restraint on reserve positions. ${ }^{6}$ The FOMC moved to a borrowed reserves operating procedure in September 1982 and switched at some point later to targeting the federal funds rate. Because the move to a funds target was not announced publicly, the timing of the switch has been the subject of some debate. Greenspan (1997) has stated that the FOMC sets "the funds rate directly in response to a wide variety of factors and forecasts" and that this has been the practice "increasingly since 1982"; this suggests that the move to funds rate targeting was gradual and that there was no precise point at which the switch occurred. Nevertheless, several researchers have attempted to date this change in procedure. Thornton (2004) claims that the move to a funds target occurred relatively soon after 1982, based on an examination of the FOMC transcripts. Bernanke and Mihov (1998), Hamilton and Jorda (2002), and Kalyvitis and Michaelides (2001) use vector autoregressions to date the move and argue that it occurred somewhat later. The findings of all of these studies indicate that the FOMC had

\footnotetext{
6 The operative sentence in the directive from the August 1997 meeting read: "In the implementation of policy for the immediate future, the Committee seeks conditions in reserve markets consistent with maintaining the federal funds rate at an average of around 5-1/2 percent." Prior to that meeting, there was no explicit reference to the desired level for the federal funds rate. For example, the operative sentence in the directive from the July 1997 meeting was: "In the implementation of policy for the immediate future, the Committee seeks to maintain the existing degree of pressure on reserve positions."
} 
switched to targeting the funds rate by 1989 , the first year in my data sample.

The bias in the policy directive, which was introduced in 1983 and discontinued in 2000, was a statement about likely future changes in the stance of monetary policy. If the likelihood of future tightening and easing were equally balanced, the bias was "symmetric." If the likelihood of future policy was unbalanced, then the bias was asymmetric in the direction of the most likely action. Thornton and Wheelock (2000) discuss three possible interpretations of the bias: that it gave the Chairman the discretion to alter policy between FOMC meetings, that it pointed to the likely course for future policy, and that it was used to build consensus among FOMC voters. Their study finds some evidence for the last of these three interpretations. ${ }^{7}$

In the next section, I discuss the construction of the preference dataset. In the third section, I use the preference data to examine several aspects of the meeting: The data indicate that Greenspan's policy proposal was almost never amended before being put to a formal vote. In addition, the rate of disagreement based on preferences was higher than the rate of official dissent, and it was higher for those policymakers who did not eventually cast an official vote than for those who did. In the subsequent section, I investigate the role played by the bias in the policy directive and whether it helped to forge consensus by looking at policymakers who changed their opinion between the voiced round and the official vote.

\section{THE PREFERENCE DATA}

The preference dataset supplements the dataset constructed by Meade and Sheets (2004) for their study of regional influences on FOMC voting behavior. Policy preferences were determined from reading the second round discussion for 72 FOMC meetings from 1989 through 1997. The dataset excludes the 12 earliest meetings in Greenspan's term (August 1987 through December

\footnotetext{
7 Most other studies of the bias look at its predictive power for future changes in short-term interest rates. For example, see Lapp and Pearce (2000).
}

1988) for two reasons: First, the structure of the first several meetings differed somewhat from the structure described above; and, second, it was sometimes difficult to sort out policymaker preferences for the interest rate, owing to some (at times considerable) confusion between the borrowed reserves target and the interest rate objective. To the extent that Greenspan's stature has risen over his tenure and, with it, the authority of his policy proposals, the exclusion of these early meetings should, ceteris paribus, bias agreement with his proposals upward (by ignoring meetings at which participants were more likely to disagree with him).

Information on preferences with respect to the short-term interest rate and the bias in the policy directive permitted the construction of three variables:

1. A multinomial variable indicating whether the policymaker expressed agreement (0), argued for a higher federal funds rate $(+1)$, or argued for a lower federal funds rate $(-1)$ relative to Greenspan's proposal.

2. A basis-point variable indicating the size of the interest rate move advocated (in basis points) relative to Greenspan's proposal for the funds rate; for example, if a policymaker wanted an increase of 50 basis points in the funds rate and Greenspan had proposed an increase of 25 basis points, this variable would be set equal to +25 . The variable would also equal +25 if a policymaker preferred to leave rates unchanged when Greenspan proposed a 25-basis-point decline. On the other hand, if a policymaker wanted a 25-basis-point increase and Greenspan proposed a 50-basis-point increase, then this variable would be set equal to -25 .

3. A multinomial variable recording whether the policymaker expressed agreement (0), argued for greater asymmetry toward tightening (+1), or argued for greater asymmetry toward easing $(-1)$ relative to Greenspan's proposal for the bias.

There were 35 individual policymakers other than Greenspan who participated in the 72 meetings covered in the dataset. The dataset records 


\section{Table 1}

\section{Preferences Recorded in Dataset: Total and by Individual Policymaker for FOMC Meetings, 1989-97}

\begin{tabular}{|c|c|c|c|}
\hline & $\begin{array}{l}\text { Variable 1: } \\
\text { directional interest rate indicator }\end{array}$ & $\begin{array}{c}\text { Variable 2: } \\
\text { basis point indicator }\end{array}$ & $\begin{array}{l}\text { Variable 3: } \\
\text { bias indicator }\end{array}$ \\
\hline Preferences coded & 1,205 & 1,162 & 1,017 \\
\hline Percent of total* & 98.4 & 94.9 & 83.0 \\
\hline \multicolumn{4}{|c|}{$\begin{array}{l}\text { Frequency distribution of } \\
\text { policymaker response rates: }\end{array}$} \\
\hline Less than $80 \%$ & 0 & 1 & 8 \\
\hline $80 \%$ to less than $90 \%$ & 1 & 3 & 13 \\
\hline $90 \%$ to less than $100 \%$ & 10 & 14 & 9 \\
\hline $100 \%$ & 24 & 17 & 5 \\
\hline \multicolumn{4}{|c|}{$\begin{array}{l}\text { Lowest response rate }(\%) \text { for an } \\
\text { individual policymaker: }\end{array}$} \\
\hline
\end{tabular}

at most one preference voiced on the interest rate and one preference voiced on the bias in the policy directive for each individual at each meeting.

There is no view recorded if no preference was expressed or if the policymaker's view was not clear. In addition, the dataset does not record a view if the policymaker was absent from a meeting or if the position was vacant at a particular meeting (opinions voiced by first vice presidents sitting in for Reserve Bank presidents were not included, and at no time during the period studied did a first vice president cast an official vote).

As shown in Table 1, policymakers expressed an opinion regarding the direction of the interest rate on 1,205 occasions (98.4 percent of the total), a view about the magnitude of the interest rate move (in basis points) on 1,162 occasions (94.9 percent of the total), and a preference for the bias in the policy directive on 1,017 occasions (83 percent of the total). The table also offers a frequency distribution of the preference data by variable: For each of the 35 policymakers, the table provides the percentage of meetings attended for which it was possible to code a preference. Coding rates were highest for preferences on the short-term interest rate, with 100 percent of meetings coded for 24 of 35 policymakers. In contrast, the bias was the most difficult to code (many policymakers did not discuss it in their second-round remarks) and only 5 of 35 policymakers have a bias preference recorded 100 percent of the time. That policymakers voiced an opinion about the short-term interest rate with greater frequency than they did about the bias in the policy directive may owe to the fact that the bias played a secondary role because it related to future policy, whereas the short-term interest rate was the immediate policy instrument. Finally, the dataset includes the 732 official votes cast by these 35 policymakers over the sample period. ${ }^{8}$

In constructing this original dataset, I exercised some judgment to ensure consistency across meetings and to remedy problems with interpretation-four examples follow. First, in a few cases, policymakers expressed indifference between Greenspan's proposal and some other alternative; these cases were coded as agreement with Greenspan. Any bias introduced by this would tend to understate the extent of voiced disagreement. Second, if a policymaker indicated that he

${ }^{8}$ Official votes were cast for an interest rate/policy bias combination. 
Table 2

Instances When Greenspan's Proposal Was Not Adopted: FOMC Meetings, 1989-97

\begin{tabular}{cccc} 
& Date of meeting & Greenspan proposal & Voted outcome \\
\hline Bias & August 1989 & Symmetric & Asymmetric $(-1)$ \\
& November 1991 & No preference & Asymmetric $(-1)$ \\
March 1994 & Asymmetric $(+1)$ & Symmetric \\
& November 1995 & No preference & Symmetric
\end{tabular}

could not decide between two different policy alternatives in the Fed staff's Bluebook, his preference was coded by averaging the two Bluebook alternatives. Third, when policymakers discussed their views in terms of the Bluebook alternatives but did not give adequate information to interpret their opinion, the Bluebook was obtained and used to remedy the confusion. ${ }^{9}$ Fourth, a preference for a "small" change in the funds rate was interpreted as equivalent to a change of 25 basis points, as this was the magnitude of the smallest change considered over most of the sample period. ${ }^{10}$

The preference dataset does not adequately reflect the complexity of the meeting debate in two circumstances when a change in policy was contingent on the success of some other policy initiative (the passage of the federal budget in October 1990) or linked to some other Fed policy change (a move in the discount rate in November 1991). Finally, as discussed in Thornton and Wheelock (2000), the transcripts reveal some disagreements with respect to the purpose of the bias in the policy directive. At times, policymakers differentiate between a "hard" and "soft" asymmetry in the policy bias, with the former indicating a greater likelihood of subsequent interest rate change than the latter. In constructing the preference dataset, I did not distinguish between these two types of asymmetry.

The dataset examines only face-to-face FOMC meetings and excludes conference calls. From 1989 through 1997, there were 39 conference calls,

9 Bluebooks from 15 FOMC meetings were used in the construction of the dataset.

${ }^{10}$ Since August 1989, the FOMC has changed its target for the funds rate in multiples of 25 basis points. most of which took place before 1995. Eighteen of the calls dealt with issues not related to the setting of the federal funds rate, while 12 were discussions of the economic situation; in the remaining 9, Greenspan announced a change in short-term interest rates. ${ }^{11} \mathrm{~A}$ formal vote was not taken during these conference calls, although, on two occasions, Greenspan proposed a change in the funds rate and solicited views from participants.

\section{WHAT DO THE PREFERENCE DATA TELL US?}

In this section, I use the dataset of voiced preferences to answer three questions:

1. How often was Greenspan's initial proposal the voted outcome of an FOMC meeting?

2. Did policymakers who did not cast an official vote behave the same as the ones who did?

3. How often did voting policymakers change their position after voicing an opinion?

Table 2 provides an answer to the first question. Greenspan's interest rate proposals were adopted by the Committee in all cases. ${ }^{12}$ With regard to the bias, on two occasions the outcome voted by the FOMC differed from Greenspan's initial proposal and on another two occasions he expressed no preference. It is not possible from

${ }^{11}$ In three of the nine instances in which Greenspan announced an adjustment to the target for the federal funds rate, the Board had voted for a change in the discount rate just prior to the conference call.

${ }^{12}$ In October 1990, Greenspan's proposal for a 25-basis-point easing was contingent on the passage of the federal budget. Although the official outcome of the meeting yielded no immediate change in the funds rate, the FOMC voted on and agreed to Greenspan's contingency action. 
Table 3

Preferences Voiced in Round 2 and Official Votes: FOMC Meetings, 1989-97

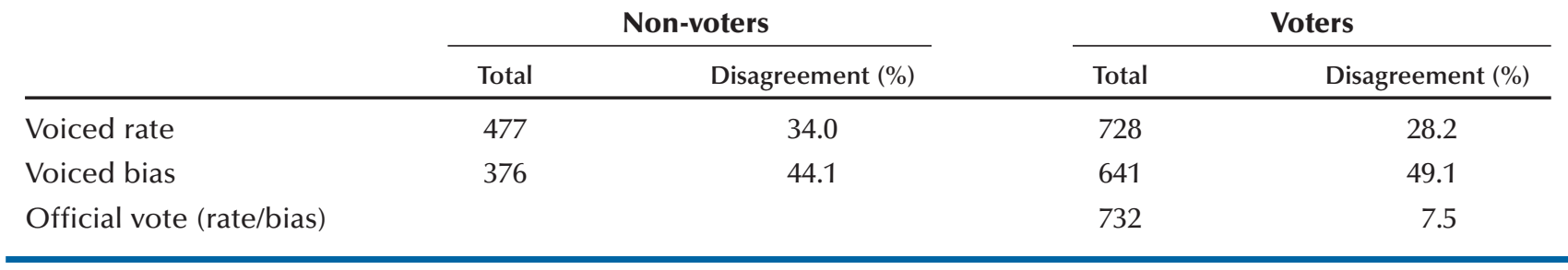

Table 2 to determine whether the success of Greenspan's proposals arose because he accurately anticipated the group's view or whether there existed some internal pressure not to disagree with him.

The answer to question 2 can be seen in Table 3, which breaks down the voiced preferences into those expressed by non-voters and those expressed by policymakers ("voters") who cast an official FOMC vote: 34 percent of non-voters voiced disagreement with Greenspan's interest rate proposal, as compared with only 28 percent of voters. Using binomial proportions, it is possible to test whether 34 percent is significantly different from 28 percent (the alternative hypothesis) against the null hypothesis that the two percentages are equal. ${ }^{13}$ The test statistic is 2.14 , and the difference in disagreement rates is statistically significant at the 5 percent level. Non-voters were less likely than voters to express disagreement with Greenspan's bias proposal—44 percent vs. 49 percent, respectively-but this difference is not statistically significant. ${ }^{14}$

More striking, however, is the disparity between the disagreement rate based on voiced preferences and the 7.5 percent dissent rate in official votes. In answer to question 3 , it is clear that voters frequently advocated one policy but voted for another. Thus, disagreement in the internal discussion cannot be ascertained by look-

\footnotetext{
13 The test statistic,

$Z=(p 1-p 2) / \sqrt{p^{*}(1-p)^{*}[(1 / n 1)+(1 / n 2)]}$

where $p 1$ is the percentage of voters voicing disagreement and $p 2$ is the percentage of non-voters voicing disagreement, is distributed approximately normally.

${ }^{14}$ The test statistic is 1.54 .
}

ing at the published votes. What explains this? It may well be the case that when a policymaker disagreed with Greenspan, but his disagreement was small, then he would voice disagreement but not cast an official dissent. This would suggest some "threshold" for the difference between the policymaker's preferred interest rate and Greenspan's proposed setting, above which a voting policymaker would dissent, but below which he would not. ${ }^{15}$ Such "threshold" behavior might reflect a belief that a large number of official dissents would weaken the Federal Reserve as an institution. It might also reflect a view that, since it is the Fed Chairman who must testify in Congress and justify monetary policy decisions, a policymaker should support the Chairman when possible. Finally, since monetary policy is a dynamic process, policymakers may desire to express their preferences during FOMC deliberations in order to have an influence on future policy, even if they do not cast a dissenting vote at that meeting. Whatever the reason for the discrepancy between voiced disagreement and official dissent, the data confirm the description of FOMC deliberations in Blinder et al. (2001).

Interestingly, a study by Epstein, Segal, and Spaeth (2001) found a very similar discrepancy in the dissent rates of official decisions and internal conference votes (9 percent vs. 40 percent, respectively) for the U.S. Supreme Court in the late 1800s. Monetary policymakers at the Bank of England have been more inclined to dissent in their official votes than FOMC members (the dissent rate averaged 17 percent from mid-1998 to

\footnotetext{
${ }^{15}$ Meade and Sheets (2004) formulate this sort of model of FOMC voting behavior.
} 


\section{Table 4}

\section{Policymakers Who Voiced Rate Disagreement in Round 2 and Cast an Official Assent: FOMC Meetings, 1989-97}

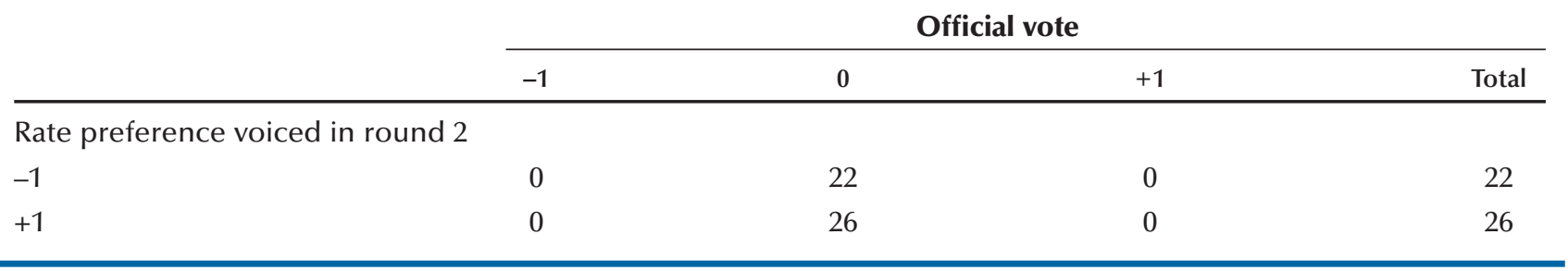

mid-2002); but, as no record of internal discussions is publicly available, it is not possible to compare their official dissent rate with their internal disagreement rate. The Bank requires its Monetary Policy Committee members to be "individually accountable" for their votes, and this requirement may tend to counteract pressure to vote as a group.

\section{THE ROLE OF THE BIAS IN THE POLICY DIRECTIVE}

Over the 1989-97 period studied in this paper, an official FOMC vote was cast for a short-term interest rate and policy bias combination. My preference dataset records views about these two "dimensions" separately. Although some studies have looked at whether the bias is a good predictor of future short-term interest rates, I am interested to examine another aspect of the bias-that it aided in the formation of consensus. Thornton and Wheelock (2000) have also tested the consensusformation hypothesis; they found that in 135 meetings from 1983-99 the FOMC was more likely to adopt asymmetric directives when it voted not to change the target for the federal funds rate. All of the prior studies that have examined the role played by the bias (consensus-formation or otherwise) have used data on the federal funds rate and the direction of the bias.

Although it is not clear at first glance how FOMC voters weighed the two "dimensions" of the decision when casting their vote, as stated earlier it seems likely that the level of the shortterm interest rate figured more importantly than the bias in the policy directive. ${ }^{16}$ Thus, I assume that an official FOMC vote represents a vote on the interest rate and can be compared to the voiced preference on that rate, and, given that assumption, I investigate the role played by the bias.

The role played by the bias is tested by examining whether voters who voiced disagreement with Greenspan's proposed interest rate but then cast an official vote in support of that interest rate could have been influenced by the bias. For example, a voter who voiced a preference for reducing short-term rates might have been willing to support Greenspan's proposal for no change in interest rates if he thought that an asymmetric bias toward easing would increase the probability that future policy would be appropriate. ${ }^{17}$ The precise test is as follows: For the voters who voice rate disagreement but cast an official assent (see Table 4), I examine whether the policy bias adopted by the FOMC goes in the direction of the original rate preference expressed by the policymaker (the alternative hypothesis) or whether the policy bias adopted appears unrelated to the original rate preference (the null hypothesis). Table 5 shows that, for 19 of 22 cases in which a policymaker voiced a preference for lower interest rates but cast an assenting vote, the adopted bias was asymmetric toward easing; for 13 of 26 cases in which

\footnotetext{
${ }^{16}$ In addition, transcripts from a number of FOMC meetings include debate among policymakers about the meaning of the bias, indicating that there was no single interpretation of its role.

${ }^{17}$ Lapp and Pearce (2000) find that an asymmetric policy directive increases the probability of a change in the federal funds target in the direction of the asymmetry. However, they do not test whether target changes are more frequent under asymmetric directives. Thornton and Wheelock (2000) do not find evidence for this latter hypothesis.
} 
Table 5

Voiced Rate Disagreement and Adopted Bias for Policymakers Who Voiced Rate Disagreement in Round 2 and Cast an Official Assent: FOMC Meetings, 1989-97

\begin{tabular}{lrrrr} 
& \multicolumn{4}{c}{ Bias adopted by FOMC } \\
\cline { 2 - 5 } & -1 & 0 & +1 & Total \\
\hline Rate preference voiced in round 2 & & & & 22 \\
-1 & 19 & 3 & 13 & 26 \\
+1 & 4 & 12 & 13 & 48 \\
Total & 23 & &
\end{tabular}

Table 6

Instances When Policymakers Voiced Rate Agreement in Round 2 and Cast an Official Dissent: FOMC Meetings, 1989-97

\begin{tabular}{lcccc} 
Meeting date & Official & Rate proposal & Desired bias & Actual bias \\
\hline March 1989 & Seger & Agree & Symmetric & Tightening \\
August 1989 & Guffey & Agree & Symmetric & Easing \\
October 1989 & Guffey & Agree & Symmetric & Easing \\
December 1991 & LaWare & Agree & Symmetric & Easing \\
June 1992 & Melzer & Agree & Symmetric & Easing \\
& LaWare & Agree & Symmetric & Easing \\
August 1992 & Melzer & Agree & Symmetric & Easing \\
& LaWare & Agree & Symmetric & Easing \\
October 1992 & Melzer & Agree & Symmetric & Easing \\
& LaWare & Agree & Symmetric & Easing \\
November 1992 & Melzer & Agree & Symmetric & Easing \\
May 1993 & LaWare & Agree & Symmetric & Easing \\
& Melzer & Agree & Symmetric & Easing \\
& Boehne & Agree & Symmetric & Tightening
\end{tabular}

a policymaker voiced a preference for higher interest rates but cast an assenting vote, the adopted bias was asymmetric toward tightening. A test of the hypothesis that the switch was related to the direction of the bias (32 of 48 cases) against the null hypothesis that the voiced rate preference and bias were independent results in a test statistic of $4.96^{18}$; the null hypothesis is rejected at the 1 percent level of significance.

${ }^{18}$ Using the normal approximation to the binomial distribution, the test statistic is normally distributed with mean equal to $n p$ and variance equal to $n p(1-p)$, where $n$ is the total number of observations and $p$ is the probability of occurrence under the null hypothesis.
This test ignores instances in which a policymaker voiced agreement with the rate proposal but subsequently voted against it. There are 14 such instances, individually documented in Table 6, and in all of these cases the voter voiced agreement with the rate proposal but cast an official dissent expressly because of the bias. Nine of these cases occurred during 1991-92, and involved two individuals-Board member LaWare and St. Louis Bank president Melzer. The FOMC transcripts indicate that LaWare and Melzer supported Greenspan's proposal for no change in the level of the funds target, but disagreed strongly with the 
asymmetric policy directive toward ease (both officials called for a symmetric bias). Greenspan made six intermeeting adjustments to the federal funds target during 1991-92, and it could be that the LaWare and Melzer dissents were a reaction to these intermeeting adjustments. It is likely that Greenspan would have had less latitude for intermeeting adjustments to the funds target under the symmetric directive favored by LaWare and Melzer. ${ }^{19}$

\section{CONCLUSION}

This paper develops and uses an original dataset collected from the internal discussion of the Fed's monetary policy committee (the FOMC transcripts) to examine questions about the Committee's behavior. The data show that Greenspan's proposals, after Committee discussion, were nearly always adopted unmodified in the formal vote. Despite the external appearance of consensus with little disagreement over decisions and an official dissent rate of 7.5 percent, the data reveal that the rate of disagreement in internal Committee discussions was quite high-on the order of 30 percent for discussions of the short-term interest rate. And, under the assumption that FOMC voters assigned a higher priority to their preferences for the short-term interest rate than the bias in the policy directive, it can be shown that this bias was important for achieving consensus, which supports and extends the results of Thornton and Wheelock (2000). Thus, the novel dataset described in this paper helps to shed some light on the internal workings of the FOMC in the Greenspan years.

\section{REFERENCES}

Bernanke, Ben S. and Mihov, Illian. "Measuring Monetary Policy." Quarterly Journal of Economics, August 1998, 113(3), pp. 869-901.

Blinder, Alan; Goodhart, Charles; Hildebrand, Philipp; Lipton, David and Wyplosz, Charles. How Do Central

\footnotetext{
${ }^{19}$ Thornton and Wheelock (2000) suggest that the Chairman has more leeway to adjust interest rates during the intermeeting period under an asymmetric directive than under a symmetric directive.
}

Banks Talk? Geneva Reports on the World Economy, Number 3, London: Centre for Economic Policy Research, 2001.

Board of Governors of the Federal Reserve System. Federal Open Market Committee Transcripts. Washington, DC: various years.

Epstein, Lee; Segal, Jeffrey and Spaeth, Harold. "The Norm of Consensus on the U.S. Supreme Court." American Journal of Political Science, April 2001, 45(2), pp. 362-77.

Greenspan, Alan. "Rules vs. Discretionary Monetary Policy." Speech delivered at Stanford University. Washington, DC: Board of Governors of the Federal Reserve System, September 1997. www.federalreserve.gov/newsevents.htm.

Greenspan, Alan. Letter to Alfonse D'Amato, Chairman of the Committee on Banking, Housing and Urban Affairs, February 21, 1995.

Hamilton, James D. and Jorda, Oscar. "A Model for the Federal Funds Rate Target." Journal of Political Economy, October 2002, 110(5), pp. 1135-67.

Kalyvitis, Sarantis and Michaelides, Alexander. "New Evidence on the Effects of US Monetary Policy on Exchange Rates." Economics Letters, May 2001, 71(2), pp. 255-63.

Lapp, John S. and Pearce, Douglas K. "Does a Bias in FOMC Policy Directives Help Predict Intermeeting Policy Changes?" Journal of Money, Credit, and Banking, August 2000, 32(3), pp. 435-41.

Meade, Ellen and Sheets, Nathan. "Regional Influences on FOMC Voting Patterns." Journal of Money, Credit and Banking, 2005 (forthcoming).

Meyer, Lawrence. A Term at the Fed. New York: Harper Collins, 2004.

Thornton, Daniel L. "When Did the FOMC Begin Targeting the Federal Funds Rate? What the Verbatim Transcripts Tell Us.” Working Paper 2004-015a, Federal Reserve Bank of St. Louis, March 2004.

Thornton, Daniel L. and Wheelock, David C. "A History of the Asymmetric Policy Directive.” Federal Reserve Bank of St. Louis Review, September/ October 2000, 82(5), pp. 1-16. 
